\title{
Prophylactic effect of dexamethasone in reducing postoperative sore throat
}

\section{Sun-young Park, Sang Hyun Kim, Ae-ri Lee, Sung-Hwan Cho, Won Seok Chae, Hee Cheol Jin, Jeong Seok Lee, and Yong Ik Kim}

Department of Anesthesiology and Pain Medicine, College of Medicine, Soonchunhyang University, Bucheon Hospital, Bucheon, Korea

Background: This study was performed to compare the effectiveness of prophylactic dexamethasone and postintubation dexamethasone in reducing the incidence and severity of postoperative sore throat (POST). Methods: This was a prospective, randomized, double-blind clinical trial. The study population consisted of 70 patients between 20 and 60 years old who were classified as American Society of Anesthesiologists III and were scheduled for elective laparoscopic cholecystectomy. The patients were divided randomly into two groups. Patients in the prophylactic and postintubation groups received intravenous injection of $10 \mathrm{mg}$ of dexamethasone $30 \mathrm{~min}$ before or after tracheal intubation, respectively. The patients were interviewed 1, 6, and $24 \mathrm{~h}$ after the operation. The incidence and severity of POST were recorded. Results: The severity scores of POST at 1 and $6 \mathrm{~h}$ after the operation were significantly lower in the prophylactic group than in the postintubation group. There were no significant differences in the incidence of POST during the $24 \mathrm{~h}$ after the operation between the two groups (22/32 in the prophylactic group vs. 27/34 in the postintubation group, P $=0.403$ ). Conclusions: Intravenous injection of $10 \mathrm{mg}$ of dexamethasone was more effective in reducing the severity of POST when administered before tracheal intubation compared with after tracheal intubation. (Korean J Anesthesiol 2010; 58: 15 19)

Key Words: Cholecystectomy, Complications, Dexamethasone, Intubation tracheal, Laparoscopic.

\section{Introduction}

Dexamethasone is a potent glucocorticoid with analgesic and anti-inflammatory effects [1-3]. It has been reported to have a prophylactic effect on postoperative nausea and vomiting $[2,4]$, and the efficacy of dexamethasone in the

Received: July 31, 2009. Revised: 1st, Auguet 13, 2009; 2nd, August 22, 2009. Accepted: October 9, 2009.

Corresponding author: Sang Hyun Kim, M.D., Department of Anesthesiology and Pain Medicine, Soonchunhyang University College of Medicine, 1174, Jung-1dong, Wonmi-gu, Bucheon 420-767, Korea. Tel: 82-32-621-5328, Fax: 82-32-621-5322, E-mail: aurellius@naver.com (c) This is an open-access article distributed under the terms of the Creative Commons Attribution Non-Commercial License (http:// creativecommons.org/licenses/by-nc/3.0/), which permits unrestricted non-commercial use, distribution, and reproduction in any medium, provided the original work is properly cited. 
treatment of sore throat has been reported $[1,5,6]$. Moreover, recent studies have demonstrated that preoperative intravenous administration of dexamethasone significantly reduces the incidence of postoperative sore throat (POST) [7, 8]. Although a minor complication, POST can cause patients a great deal of discomfort. It is difficult to control, even when the operative pain has been successfully controlled by the administration of systemic analgesics. Therefore, the prevention of POST is an important issue.

As previous studies only compared prophylactic dexamethasone and placebo groups, the present study compared the effectiveness of prophylactic dexamethasone and postintubation dexamethasone in reducing the incidence and severity of POST.

\section{Materials and Methods}

This was a prospective, randomized, double-blind clinical trial and was approved by the institutional review board. After obtaining written informed consent, 70 patients between 20 and 60 years of age with American Society of Anesthesiologists physical status I-II who were scheduled for elective laparoscopic cholecystectomy were enrolled in this study between March 2009 and July 2009. Exclusion criteria included a history of recent respiratory tract infection or sore throat, and preoperative use of analgesics or steroids. Patients who changed head position during surgery, required more than one attempt for tracheal intubation, had a nasogastric tube, had a duration of tracheal intubation of $<60 \mathrm{~min}$ or $>300$ min, or vomited during the study period were eliminated from the analysis.

Before surgery, the patients were divided randomly into two groups, using a computer-generated random number table and the sealed envelope method. Patients in the prophylactic group were injected with $10 \mathrm{mg}$ of dexamethasone intravenously 30 min before tracheal intubation, whereas those in the postintubation group received an injection of $10 \mathrm{mg}$ of dexamethasone after tracheal intubation. When one group received dexamethasone, the other was injected with $2 \mathrm{ml}$ of normal saline. All anesthetic procedures were performed by experienced anesthesiologists who were blinded to the group allocation. The investigators who collected data and interviewed patients did not perform any of the procedures and were blinded to the group allocation. All patients were blinded to the group allocation.

Patients were premedicated by intramuscular injection of $0.2 \mathrm{mg}$ of glycopyrrolate. In the operating room, monitoring consisted of three-lead electrocardiography, noninvasive arterial blood pressure, pulse oximetry, and end-tidal $\mathrm{CO}_{2}$. Induction was accomplished with fentanyl $(100 \mu \mathrm{g})$ and propofol (2 mg/kg), followed by rocuronium ( $0.6 \mathrm{mg} / \mathrm{kg}$ ). Before intubation, ventilation was controlled with 100\% oxygen via a face mask. Direct laryngoscopy with a Macintosh \#3 blade and tracheal intubation were performed 3 min after rocuronium injection. The trachea was intubated with a high volume/low pressure endotracheal tube (Euromedical, Kedah, Malaysia) with an internal diameter of 8.0 or $7.0 \mathrm{~mm}$ for male or female patients, respectively. The tracheal tube was lubricated with chlorhexidine gluconate jelly. Immediately after intubation, the tracheal tube cuff was inflated with room air until no air leakage could be heard at a peak airway pressure of $20 \mathrm{~cm} \mathrm{H}_{2} \mathrm{O}$. Then, the cuff pressure was adjusted to between 10 and $20 \mathrm{~cm} \mathrm{H}_{2} \mathrm{O}$ using a handheld pressure gauge (Portex Cuff Inflator/Pressure Gauge; SIMS Portex, Hythe, Kent, UK). No humidifiers or heat and moisture exchangers were used in either group. Anesthesia was maintained with 50\% $\mathrm{O}_{2}$ in air, 7-8 vol\% desflurane, and rocuronium. The end-tidal $\mathrm{CO}_{2}$ was kept between 35 and $40 \mathrm{mmHg}$.

At the end of surgery, the patients were given pyridostigmine $(10 \mathrm{mg})$ and glycopyrrolate $(0.2 \mathrm{mg})$ intravenously, and the lungs were ventilated with $100 \% \mathrm{O}_{2}$ until the patient was fully awake and had recovered from the muscle relaxant. After gentle aspiration of the oral secretions, the cuff was deflated fully and the tracheal tube was removed. The patients were administered $\mathrm{O}_{2}$ via a face mask and transferred to the postanesthesia care unit. Coughing during tracheal extubation, the presence of blood in the oropharyngeal secretion or on the tracheal tube after extubation, and the duration of tracheal intubation were recorded. All patients received intravenous fentanyl after the operation when they complained of operative wound pain. We did not restrict the use of fentanyl postoperatively, but no other analgesics were used.

The incidences and severities of POST, cough, and hoarseness were measured using direct questions [9] at 1, 6, and $24 \mathrm{~h}$ after the operation. The severities of POST, cough, and hoarseness were graded using a 4-point scale (Table 1). Visual analog scale (VAS) scores of wound pain were recorded at the same times. The total dose of fentanyl administered during induction and for $24 \mathrm{~h}$ after the operation was also recorded.

For statistical analysis, the t-test was used for comparisons between group differences in age, weight, duration of tracheal intubation, wound pain VAS score, and the total dose of fentanyl administered during induction and for $24 \mathrm{~h}$ after the operation. The $\chi^{2}$ test was used for comparisons between group differences in gender and ASA status. Between-group differences in the incidences of coughing during tracheal extubation, the presence of blood in the oropharyngeal secretions or on the tracheal tube after extubation, and POST, cough, and hoarseness for $24 \mathrm{~h}$ after the operation as well as differences in the severity scores for POST, cough, and hoarseness were analyzed using the $\chi^{2}$ test and Fisher's exact test as appropriate. The results are expressed as the mean \pm $\mathrm{SD}$, absolute number, or median and the range of 25 th- 75 th 
percentiles. Values of $\mathrm{P}<0.05$ were considered significant.

The primary outcome variable of this study was the incidence of POST during the $24 \mathrm{~h}$ after the operation. Secondary outcome variables included the severity of POST, cough, and hoarseness, and the incidences of cough and hoarseness during the $24 \mathrm{~h}$ after the operation.

The sample size was estimated from preliminary data obtained from 50 patients and the assumption that a 50\% reduction in the incidence of POST would be clinically relevant. Power analysis suggested that a minimum of 31 patients in each group would be needed for $\beta=0.20$ and

Table 1. Scoring System for Sore Throat, Cough, and Hoarseness

\begin{tabular}{cl}
\hline Severity score & \multicolumn{1}{c}{ Description } \\
\hline $\begin{array}{c}\text { Sore throat } \\
0\end{array}$ & No sore throat \\
1 & Minimal sore throat \\
3 & Moderate sore throat \\
Cough & Severe sore throat \\
0 & \\
1 & No cough \\
2 & Minimal cough \\
3 & Moderate cough \\
Hoarseness & Severe cough \\
0 & \\
1 & No hoarseness \\
2 & Hoarseness at the time of interview, \\
3 & but noted only by patient \\
& Hoarseness that is readily apparent, but mild \\
& severe
\end{tabular}

$a=0.05$. To compensate for potential dropouts, 70 patients were enrolled.

\section{Results}

Of the 70 patients enrolled in this study, four were excluded from the analysis ( 3 in the prophylactic group and 1 in the postintubation group): one patient required more than one intubation attempt, and three vomited during the study period. The characteristics of the remaining 66 subjects are summarized in Table 2. No significant differences were observed between the two groups with respect to age, gender, weight, ASA status, duration of tracheal intubation, incidence of coughing during extubation, or the presence of blood in the secretions or tube. The total doses of fentanyl administered during induction and for $24 \mathrm{~h}$ after the operation and the wound pain VAS scores were comparable between the two groups.

There were no significant differences in the incidence of POST during the $24 \mathrm{~h}$ after the operation between the two groups (22/32 in the prophylactic group vs. 27/34 in the postintubation group, $\mathrm{P}=0.403)$. There were no significant differences in the incidences of cough ( $9 / 32$ vs. $4 / 34, P=$ $0.126)$ or hoarseness (26/32 vs. $21 / 34, P=0.106)$ between the two groups.

The severity scores of POST at $1 \mathrm{~h}$ and $6 \mathrm{~h}$ after the operation were significantly lower in the prophylactic group than in the postintubation group. There were no significant differences in the severity of cough or hoarseness between the two groups (Table 3).

\section{Discussion}

Although the two groups did not differ significantly in the

Table 2. Patient Characteristics

\begin{tabular}{|c|c|c|c|}
\hline Groups & Prophylactic group ( $\mathrm{n}=32$ ) & Postintubation group $(n=34)$ & $P$ values \\
\hline Age (yr) & $44.0 \pm 9.5$ & $40.3 \pm 9.9$ & 0.134 \\
\hline Gender (M/F) & $10 / 22$ & $9 / 25$ & 0.787 \\
\hline Weight (kg) & $62.2 \pm 11.8$ & $63.0 \pm 11.9$ & 0.777 \\
\hline ASA (I/II) & $25 / 7$ & $30 / 4$ & 0.333 \\
\hline Duration of tracheal intubation (min) & $96.8 \pm 20.6$ & $109.2 \pm 38.5$ & 0.107 \\
\hline Coughing during extubation & 21 & 28 & 0.162 \\
\hline Blood in the secretions or tube & 3 & 0 & 0.108 \\
\hline Doses of fentanyl administered $(\mu \mathrm{g})$ & $146.7 \pm 40.6$ & $135.2 \pm 41.7$ & 0.267 \\
\hline \multicolumn{4}{|l|}{ Wound pain VAS (0-10) } \\
\hline $1 \mathrm{~h}$ & $6(4.4-6.2)$ & $5(3.6-5.9)$ & 0.400 \\
\hline $6 \mathrm{~h}$ & $4(3.4-4.8)$ & $3(2.8-4.8)$ & 0.586 \\
\hline $24 \mathrm{~h}$ & $2(2.1-3.3)$ & $1(1.4-2.9)$ & 0.253 \\
\hline
\end{tabular}

Data are given as the mean \pm SD or absolute numbers or median (25-75th percentiles). No significant differences were found between the groups. 
Table 3. Severity Scores of Postoperative Sore Throat, Cough, and Hoarseness

\begin{tabular}{|c|c|c|c|c|c|c|}
\hline \multirow{2}{*}{ Severity by score } & \multicolumn{3}{|c|}{ Prophylactic group $(n=32)$} & \multicolumn{3}{|c|}{ Postintubation group $(n=34)$} \\
\hline & $1 \mathrm{~h}$ & $6 \mathrm{~h}$ & $24 \mathrm{~h}$ & $1 \mathrm{~h}$ & $6 \mathrm{~h}$ & $24 \mathrm{~h}$ \\
\hline Sore throat & $*$ & * & & & & \\
\hline 0 & 12 & 11 & 23 & 12 & 15 & 25 \\
\hline 1 & 12 & 17 & 6 & 8 & 6 & 6 \\
\hline 2 & 6 & 3 & 3 & 3 & 7 & 3 \\
\hline 3 & 2 & 1 & 0 & 11 & 6 & 0 \\
\hline \multicolumn{7}{|l|}{ Cough } \\
\hline 0 & 31 & 25 & 26 & 34 & 30 & 33 \\
\hline 1 & 1 & 6 & 6 & 0 & 4 & 1 \\
\hline 2 & 0 & 1 & 0 & 0 & 0 & 0 \\
\hline 3 & 0 & 0 & 0 & 0 & 0 & 0 \\
\hline \multicolumn{7}{|l|}{ Hoarseness } \\
\hline 0 & 10 & 7 & 14 & 19 & 16 & 27 \\
\hline 1 & 2 & 9 & 12 & 3 & 9 & 5 \\
\hline 2 & 9 & 12 & 5 & 3 & 7 & 1 \\
\hline 3 & 11 & 4 & 1 & 9 & 2 & 1 \\
\hline
\end{tabular}

Data are the numbers of patients. ${ }^{*} \mathrm{P}<0.05$ compared postintubation group.

incidence of POST during the $24 \mathrm{~h}$ after surgery, the severity scores of POST at $1 \mathrm{~h}$ and $6 \mathrm{~h}$ after the operation were significantly lower in the prophylactic group than in the postintubation group.

We used the same dose of dexamethasone in both groups and controlled confounding factors that can affect POST, including type of endotracheal tube, type of cuff and intracuff pressure [10], type of operation, and duration of tracheal intubation. In addition, the same analgesics were used in all subjects in both groups, and we confirmed that the severity of postoperative pain and the dose of analgesics used during the study period were not different between the groups, thus excluding potential distraction effects. Therefore, the differences in the severity scores of POST were attributable only to the difference in the timing of dexamethasone administration.

Thomas and Beevi [8] investigated the effects of preoperatively administered dexamethasone on POST and concluded that prophylactic intravenous dexamethasone $(8 \mathrm{mg})$ reduces the incidence and severity of POST following tracheal intubation. Park et al. [7] showed that the prophylactic use of $0.2 \mathrm{mg} / \mathrm{kg}$ of dexamethasone significantly decreased the incidence and severity of sore throat and hoarseness at 1 and $24 \mathrm{~h}$ after tracheal extubation of a double-lumen endobronchial tube. The potential mechanism is presumably based on the anti-inflammatory activity of dexamethasone, which includes inhibition of leukocyte migration and maintenance of cell membrane integrity. In addition, this effect may be increased when dexamethasone is administered before laryngeal trauma.
In previous studies that evaluated the effectiveness of dexamethasone in the prevention of POST after tracheal intubation, the preoperative administration of intravenous dexamethasone was compared with placebo. In the present study, to validate the prophylactic effect, we compared the effects of dexamethasone administered before versus after tracheal intubation. Compared with dexamethasone administration after tracheal intubation, the administration of dexamethasone before tracheal intubation gave a greater beneficial effect on the severity of POST, supporting the prophylactic use of dexamethasone.

We used a single 10-mg dose of dexamethasone, which was similar to the doses used in previous studies. Potential side effects of dexamethasone include hyperglycemia, peptic ulcer, increased susceptibility to infection, and electrolyte imbalance. However, the risk of side effects from single-dose steroid therapy seems to be negligible [11].

The incidence of POST in our study was higher than expected [7,8,12-14]. The tracheal tube might have been relatively large for our patients [15], and although we adjusted the intracuff pressure, it was probably higher in our patients than in previous studies because of the increased abdominal pressure created by the $\mathrm{CO}_{2}$ gas [10]. In addition, there were more female patients than male patients in our series, which might have increased the incidence of POST [16]. Laparoscopic cholecystectomy is a minimally invasive operation associated with mild pain, and therefore the patients received relatively low doses of systemic analgesics. This may also explain the high incidence of POST.

Although previous studies have demonstrated the efficacy 
of dexamethasone for the prevention of POST after tracheal intubation, the present study was performed to investigate the influence of administration time. In addition, the prophylactic effectiveness of dexamethasone in reducing the severity of POST was verified.

In conclusion, for reducing the severity of POST, the administration of intravenous dexamethasone $(10 \mathrm{mg})$ before tracheal intubation was more effective than the administration after tracheal intubation.

\section{References}

1. Baxendale BR, Vater M, Lavery KM. Dexamethasone reduces pain and swelling following extraction of third molar teeth. Anaesthesia 1993; 48: 961-4.

2. Elhakim M, Ali NM, Rashed I, Raid MK, Refat M. Dexamethasone reduces postoperative vomiting and pain after pediatric tonsillectomy. Can J Anesth 2003; 50: 392-7.

3. Schmelzeisen R, Frölich JC. Prevention of postoperative swelling and pain by dexamethasone after operative removal of impacted third molar teeth. Eur J Clin Pharmacol 1993; 44: 275-7.

4. Wang JJ, Ho ST, Lee SC, Liu YC, Liu YH, Liao YC. The prophylactic effect of dexamethasone on postoperative nausea and vomiting in women undergoing thyroidectomy: a comparison of droperidol with saline. Anesth Analg 1999; 89: 200-3.

5. Wei JL, Kasperbauer JL, Weaver MS, Boggust AJ. Efficacy of single-dose dexamethasone as adjuvant therapy for acute pharyngitis. Laryngoscope 2002; 112: 87-93.

6. Roy M, Bailey B, Amre DK, Girodias JB, Bussières JF, Gaudreault P. Dexamethasone for the treatment of sore throat in children with suspected infectious mononucleosis: a randomized, double-blind, placebo-controlled, clinical trial. Arch Pediatr Adolesc Med 2004; 158:
250-4.

7. Park SH, Han SH, Do SH, Kim JW, Rhee KY, Kim JH. Prophylactic dexamethasone decreases the incidence of sore throat and hoarseness after tracheal extubation with a double-lumen endobronchial tube. Anesth Analg 2008; 107: 1814-8.

8. Thomas S, Beevi S. Dexamethasone reduces the severity of postoperative sore throat. Can J Anaesth 2007; 54: 897901.

9. Harding CJ, McVey FK. Interview method affects incidence of postoperative sore throat. Anaesthesia 1987; 42: 1104 7.

10. Combes X, Schauvliege F, Peyrouset O, Motamed C, Kirov K, Dhonneur G, et al. Intracuff pressure and tracheal morbidity: influence of filling with saline during nitrous oxide anesthesia. Anesthesiology 2001; 95: 1120-4.

11. Jokela RM, Ahonen JV, Tallgren MK, Marjakangas PC, Korttila KT. The effective analgesic dose of dexamethasone after laparoscopic hysterectomy. Anesth Analg 2009; 109: 607-15.

12. Christensen AM, Willemoes-Larsen $H$, Lundby L, Jakobsen KB. Postoperative throat complaints after tracheal intubation. Br J Anaesth 1994; 73: 786-7.

13. McHardy FE, Chung F. Postoperative sore throat: cause, prevention and treatment. Anaesthesia 1999; 54: 444-53.

14. Canbay O, Celebi N, Sahin A, Celiker V, Ozgen S, Aypar $U$. Ketamine gargle for attenuating postoperative sore throat. Br J Anaesth 2008; 100: 490-3.

15. Stout DM, Bishop MJ, Dwersteg JF, Cullen BF. Correlation of endotracheal tube size with sore throat and hoarseness following general anesthesia. Anesthesiology 1987; 67: 419-21.

16. Maruyama K, Sakai H, Miyazawa H, Toda N, linuma $Y$, Mochizuki N, et al. Sore throat and hoarseness after total intravenous anaesthesia. Br J Anaesth 2004; 92: 541-3. 